\title{
Adaptation of flowering phenology and fitness-related traits across environmental gradients in the widespread Campanula rotundifolia
}

\author{
Veronica Preite • Jürg Stöcklin • Georg F. J. Armbruster • \\ J. F. Scheepens
}

Received: 4 July 2014/Accepted: 22 January 2015/Published online: 7 February 2015

(C) Springer International Publishing Switzerland 2015

\begin{abstract}
Plant populations need to adjust to climate warming through phenotypic plasticity or evolution of trait means. We performed a common-garden experiment with European populations of Campanula rotundifolia to investigate current adaptation in fitness-related traits and the potential for future adaptation. The common garden was situated in Switzerland and contained plants from 18 populations from four regions: Central Europe, The Netherlands, Scandinavia and the Swiss Alps. We assessed current adaptation with trait-environment correlations, and we compared molecular marker with trait differentiation to investigate past selection. How traits may change under future climate warming was investigated via selection analysis. Trait-trait correlations were performed to reveal genetic constraints. The majority of analysed phenotypic traits showed regional differentiation and all traits showed indications of past selection. Flowering duration decreased with latitude and elevation, suggesting adaptation to growing season length. The Central European populations performed best, indicating home-site advantage. Selection analysis showed positive selection on fitness-related traits whereas phenological traits showed less clear patterns. Trait-trait correlations were mostly neutral or favourable to selection. This study suggests that flowering phenology and other fitness-related traits of
\end{abstract}

Electronic supplementary material The online version of this article (doi:10.1007/s10682-015-9754-y) contains supplementary material, which is available to authorized users.

V. Preite $(\bowtie) \cdot$ J. Stöcklin · G. F. J. Armbruster · J. F. Scheepens

Section of Plant Ecology, Institute of Botany, University of Basel, Schönbeinstrasse 6, 4056 Basel, Switzerland

e-mail: v.preite@nioo.knaw.nl

Present Address:

V. Preite

Department of Terrestrial Ecology, Netherlands Institute of Ecology (NIOO-KNAW),

Droevendaalsesteeg 10, 6708 PB Wageningen, The Netherlands

J. F. Scheepens

Plant Evolutionary Ecology, Institute of Evolution and Ecology, University of Tübingen, Auf der Morgenstelle 5, 72076 Tübingen, Germany 
C. rotundifolia are adapted to the current climatic conditions and have the potential to evolve under climate change.

Keywords Adaptation - Campanula rotundifolia - Environmental gradients · Flowering phenology $\cdot Q_{\mathrm{ST}}-F_{\mathrm{ST}}$ comparison $\cdot$ Selection analysis

\section{Introduction}

Many plant populations have to cope with rapid climate and land-use changes (IPCC 2013). In Europe, the dominant climatic changes are reduced precipitation in Southern Europe, increased precipitation in Northern Europe and overall increased mean temperatures. These climatic changes may cause locally adapted plant populations to shift poleward or towards higher elevations (Davis and Shaw 2001; Walther 2003). However, in increasingly fragmented landscapes the necessary migration rate needed to track climate change is probably too high for most plant species (Davis and Shaw 2001; Jump and Peñuelas 2005; Shaw and Etterson 2012). As alternative to migration, populations can adjust to changing climatic conditions, through phenotypic plasticity or through evolution of trait means or through evolution of plasticity itself (Joshi et al. 2001; Shaw and Etterson 2012).

Phenotypic plasticity allows plant populations to survive under a range of conditions without the need for changes through selection. To adapt to new conditions under rapid climate change, plastic responses may not suffice and evolution of mean trait values (or of plastic responses) is needed (Ghalambor et al. 2007). Successful genetic adaptation under rapid climate change therefore requires, besides a short generation time, variability in fitness-related traits that is at least partly genetically based and heritable (Houle 1992). Predicting a population's potential to adapt to climate change requires assessment of which traits are currently adapted to climatic factors and should therefore also adapt under climate change and whether trait-trait correlations may hamper adaptation of sets of traits to future climates (Lande and Arnold 1983).

Genetically fixed clinal variation in phenotypic traits has often been found to correlate with environmental gradients, suggesting current adaptation to local conditions (Turesson 1930; Montague et al. 2008; Monty and Mahy 2009; Paccard et al. 2014). Particularly the phenology of widespread species often shows strong variation along latitudinal and elevation gradients, suggesting adaptation to clinally changing climatic conditions (Turesson 1930; Briggs and Walters 1997; Clevering et al. 2001; Olsson and Ågren 2002; Montague et al. 2008). For instance, common-garden experiments showed that with increasing latitude of origin the start of flowering advanced and growing and flowering duration shortened for Potentilla glandulosa (Clausen et al. 1947), for two Solidago species (Weber and Schmid 1998) and for Lythrum salicaria (Olsson and Ågren 2002; Montague et al. 2008).

In this study we performed a common-garden experiment with Campanula rotundifolia L., the harebell, using accessions from a latitudinal and an elevation gradient to investigate current clinal adaptation of flowering phenology and other ecologically relevant traits (Linhart and Grant 1996). The experiment in the common garden consisted of C. rotundifolia from home site populations as well as foreign populations. The home site plants originated from the same geographic region as the experimental garden in Central Europe and the foreign plants originated from higher latitudes (Scandinavia, The Netherlands) or elevations (Swiss Alps). For the foreign populations the common garden represents a 
warmer environment and therefore this design allows insight in plant fitness and trait responses under future global warming. In contrast to broad regional adaptation to climate, populations may respond variably to competition depending on their local evolutionary history. To investigate this, we added Bromus erectus Huds. as competitor to half of the experimental plants.

Observing correlations between trait values measured in a common garden and climatic conditions at sites of origin suggest that phenotypic clines are adaptive, but trait variation may also be a result of genetic drift. To infer past selection pressures on the observed traits we analysed the molecular differentiation among the sampled populations, using RAPD markers, which can be used in $Q_{\mathrm{ST}}-F_{\mathrm{ST}}$ comparisons (Merilä and Crnokrak 2001; Scheepens et al. 2010). Furthermore, selection analysis was used to investigate current selection on traits in the common garden, i.e. under mimicked future climatic conditions, and genetic correlations between traits were performed to identify constraints to adaptation to a warmer climate.

In summary, the objectives of this study were: (1) to test for clinal variation across latitude and elevation in phenological and fitness-related traits; (2) to investigate whether selection acted on traits in the past; (3) to investigate which traits are under selection under the mimicked future climatic conditions in the common garden; (4) to investigate whether adaptation of phenotypic traits to future climate change may be hampered by genetic constraints.

\section{Materials and methods}

Study species and sampling design

The perennial herb, C. rotundifolia L. (Campanulaceae), is widespread in the boreo-temperate zone of the northern hemisphere (Stevens et al. 2012). In Europe, the species ranges

Fig. 1 Map of sampling sites of C. rotundifolia, with five populations in SC (Scandinavia), five populations in NL (The Netherlands), five populations in $\mathrm{CE}$ (Central Europe) and three populations in AL (Swiss Alps). Detailed description of the population sites are given in Table S1 in the Appendix

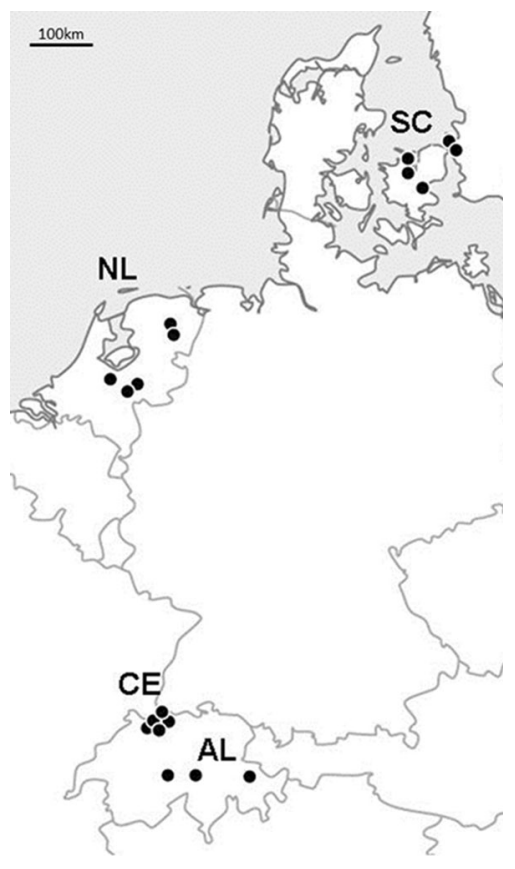


from Spitsbergen (Engelskjøn et al. 2003) to Greece (Blionis et al. 2001), and from sea level to subalpine zones (Stevens et al. 2012; highest occurrence in the European Alps 1,697 $\mathrm{m}$ above sea level, E.S. Frei, personal observation). The species mainly inhabits grasslands, favours nutrient-poor sites (Lauber and Wagner 1998; Stevens et al. 2012) and is sensitive to land-use changes (Lindborg et al. 2005; Stevens et al. 2012). Within one growing season the plant forms a rosette which partly dies back during flowering. Upon flowering, one to several flowering stems are formed, each with one or more violet, bellshaped flowers (Stevens et al. 2012). The self-incompatible plant is insect-pollinated, usually by bees (Shetler 1982; Bingham and Orthner 1998). Its seeds do not have obvious dispersal adaptations but, due to their low weight, may be dispersed by wind and water (Shetler 1982; Nyman 1992).

Leaf material and seed capsules bearing seeds were sampled while keeping a minimum distance of one meter between each sampled plant to avoid sampling clones, since clonal reproduction has been observed occasionally (Lindborg et al. 2005). Leaf material was dried and stored with silica gel until DNA extraction. Offspring of seed samples are referred to as seed families. We sampled 104 plants, nested in 18 populations and four regions (Fig. 1; Table S1 in the Appendix). Three of the four regions were selected along a latitudinal gradient: Scandinavia (five populations), The Netherlands (five populations) and Central Europe (five populations). The fourth region is located in the Swiss Alps (three populations) at comparatively high elevation (Table S1). The sampling sites in The Netherlands and Scandinavia are characterised by cooler and drier summer conditions compared to Central European sites. Sites in the Alpine region are characterised by cooler and wetter conditions during the growing season compared to Central European sites (Table S1).

\section{Common-garden experiment}

The common garden was located in the Botanical Garden of Basel, Switzerland

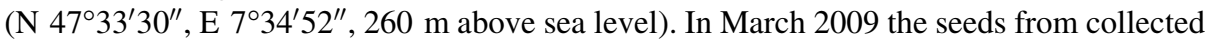
capsules were germinated on water-saturated filter paper in Petri dishes, which were kept in a growing chamber $\left(12 \mathrm{~h} \mathrm{light} / 12 \mathrm{~h}\right.$ dark; $\left.20{ }^{\circ} \mathrm{C} / 10{ }^{\circ} \mathrm{C}\right)$ and moistened daily if necessary. After 20 days the seedlings reached the stage with one true leaf and were transplanted in trays with 54 pots $(5 \mathrm{~cm}$ diameter $\times 5 \mathrm{~cm}$ height $)$ filled with low nutrient soil (Anzuchterde, Ökohum, Herrenhof, Switzerland). The seedlings were kept in the greenhouse, watered daily, and were protected against drought with a fine-mesh cloth. Early in May, seedlings were transplanted into larger pots $(10 \times 10 \times 10 \mathrm{~cm})$ with the same soil type. To balance the design at the population level, each population contained 56 offspring (except for population KIE which had 57 offspring) from two to seven seed families depending on the available number of seed families, resulting in 1,009 plants in total (Table S1). Half of the offspring per seed family received a competition treatment, i.e. four seedlings of $B$. erectus Huds. s.str. (Poaceae) were added in the corners of the pots. $B$. erectus is a grass species widespread in Europe and frequently co-occurring in vegetation communities with $C$. rotundifolia. Its vigorous root growth makes it a suitable competitor in this experiment.

One week after the transplantation in the greenhouse, 14th May 2009, all pots were placed outdoors in the Botanical Garden, in trays holding 24 pots. The plants were watered regularly and protected from snails (Ferramol ${ }^{\circledR}$, Biocontrol, Andermatt, Switzerland). During the experiment the position of the Petri dishes and trays were randomized twice a week. Two to three times per week, we scored the flowering start (i.e. the first date when 
there is at least one flower in anthesis) and the flowering end (i.e. the first date when all flowers on a plant had withered). From this data, flowering (yes/no) and the duration of flowering were deduced. During 1st-9th July 2009 rosette leaves were counted, and the length of the longest flowering stem of each plant was measured. To include accumulated dead leaves in the total above-ground biomass production, the shed rosette leaves were regularly sampled. To assess reproductive output, ripe capsules were collected and counted throughout the season. The number of seeds would be a better measure of reproductive output but in $C$. rotundifolia this trait is an unreliable measure since ripening capsules might lose seeds before sampling. End of October, when the plants started to wither, flowering stems were counted and above-ground biomass of the plants was harvested and dried for $72 \mathrm{~h}$ at $60{ }^{\circ} \mathrm{C}$. The total above-ground biomass included dried biomass plus litter and capsules. We scored the plants' overall survival by assessing whether plants were alive or dead at the time of harvest.

\section{Climate data}

We obtained weather data of 2009 from a meteorological station close to the common garden. The historical climate data for the common garden and population origins were based on measurements from WorldClim from 1950-2000 (Hijmans et al. 2005), from which temperature means, temperature ranges (calculated as the mean of the difference between monthly maximum and minimum temperatures), and precipitation sums for JuneAugust were derived (Table S1). Of the four WorldClim data points surrounding a sampling site, the one with the least elevation difference to the location of origin was chosen for each population, and the mean temperature values were corrected by $0.0055{ }^{\circ} \mathrm{C}$ per meter elevation difference (Ozenda 1988).

The botanical garden experienced a relatively warm and dry summer in 2009 , with mean temperature of $20.0{ }^{\circ} \mathrm{C}$ for the summer months June-August, which deviated from the climatic average of $18.1{ }^{\circ} \mathrm{C}$. The experienced temperature was also higher than climate averages at all population origins. Thus, the common garden simulated a warmed environment for plants from all populations (Table S1), although the Central European home-site populations may be adapted to the experienced summer temperature. The laissez-faire RCP8.5 scenario of IPCC predicts an increase of $2.6-4.8{ }^{\circ} \mathrm{C}$ in global mean surface air temperature at the end of this century (IPCC 2013). This temperature increase was mimicked in the common garden for all sampled populations except for those from the Swiss Alps, for which the increase of $10.1{ }^{\circ} \mathrm{C}$ was outside the boundaries of any IPCC prediction. The observed temperature range in 2009 in the common garden $\left(21.6^{\circ} \mathrm{C}\right)$ was markedly higher compared to the long-time climatic averages at all plant origins (Table S1) and in the common garden $\left(10.8{ }^{\circ} \mathrm{C}\right)$.

\section{Trait differentiation analysis}

Because start and end of flowering are occurring through time (i.e. so-called time-to-event data), these traits were analysed by comparing Kaplan-Meier survival curves based on Cox proportional hazards regression models. We used the function $\operatorname{coxph}()$ from R-package survival version 2.37-2 (Therneau 2012) in R (Version 3.1.0; R Development Core Team 2009). The survival analysis included competition, region and their interaction and was based on a sample size of 586 plants. We assumed that plants that survived but did not flower during the experiment would not flower that same season if left standing (i.e. we had only uncensored data). For statistical analyses of all other traits, hierarchical generalised mixed-effects models were performed using the function $\operatorname{lmer}($ ) from the R-package lme 4 
version 1.1-6 (Bates et al. 2014) while applying the package lmerTest version 2.0-6 (Kuznetsova et al. 2014). The following factors were tested: competition (fixed), region (fixed), population nested in region (random), seed family nested in population (random), competition $\times$ region interaction (fixed), competition $\times$ population interaction (random) and competition $\times$ seed family interaction (random). $F$ values were calculated for fixed effects and $\chi^{2}$ values for random effects, whereas their $P$ values were calculated using Satterthwaite's method. Mortality-related deviating numbers of seed families included in the analyses are shown in Table S2 in the Appendix. To locate significant differences among regions, Tukey HSD tests were performed using the function $g l h t()$ from package multcomp version 1.3-1 (Bretz et al. 2010). Flowering and survival data were analysed using a binomial distribution and number of stems was analysed using a Poisson distribution. All other response variables fit a normal distribution. To improve the normality of the model residuals we used a square-root transformation for flowering duration, number of leaves, stem length, number of capsules and above-ground biomass.

To assess local adaptation to environmental conditions Pearson's correlations were performed between population means of measured traits and latitude (for the Scandinavian, Dutch and Central European populations), elevation (for Central European and Alpine populations), temperature means, temperature ranges and precipitation sums for JuneAugust (for both sets of regions separately). To limit multicollinearity among the environmental variables and observed traits, we calculated variance inflation factors (VIF) using the function vif() in R-package $H H$ version 2.3-42 (Heiberger and Holland 2004) using 5.0 as an arbitrary threshold value for acceptable multicollinearity. For the latitude dataset, we excluded flowering, number of leaves and above-ground biomass, resulting in VIFs below 4.5. For the elevation dataset, we additionally excluded number of capsules, resulting in VIFs below 3.7 accept for stem length (5.4), which we ignored. For the latitude and elevation datasets, temperature mean, temperature range and precipitation sum had VIFs below 3.9 and 3.3 , respectively.

\section{Molecular analysis}

For the molecular analysis 15 out of 18 populations were considered (Table S1). Genomic DNA was extracted from dried and grinded (Retsch MM400, Retsch GmbH and Co KG, Haan, Germany) field-collected leaf material of 13 accessions per population using the DNeasy Plant Mini Kit (QIAGEN, Hombrechtikon, Switzerland). DNA concentration was measured using NanoDrop ${ }^{\text {TM }}$ (ND-1000, Witec, Littau, Switzerland) and adjusted to $1 \mathrm{ng} \mu \mathrm{L}^{-1}$. The following five primers were chosen for fingerprinting based on their high polymorphism, quantity and quality of bands: X5 = CggTCACTgT, M6 = gTgggCTgAC, $\mathrm{H} 2=\mathrm{TCggACgTgA}, \mathrm{H} 13=$ gACgCCACAC, and $\mathrm{H} 20=\operatorname{gggAgACATC}$ (Eurofins MWG Synthesis, Ebersberg, Germany). RAPD-PCR was performed with self-dissolving illustra $^{\text {TM }}$ PuReTaq Ready-To-Go PCR Beads (GE Healthcare, Buckinghamshire, UK). The beads contained $10 \mathrm{mM}$ Tris-HCl buffer, $200 \mu \mathrm{M}$ dNTPs, $1.5 \mathrm{mM} \mathrm{MgCl} 2,50 \mathrm{mM}$ $\mathrm{KCl}$ and $\sim 2.5$ units of recombinant PuReTaq DNA polymerase. The beads were dissolved

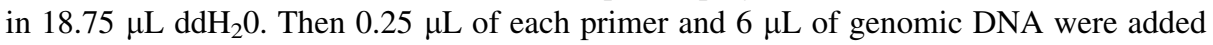
before the amplification. PCRs were run in an Eppendorf Mastercycler Gradient (Eppendorf, Hamburg, Germany) with the following cycling scheme: 2 min at $94{ }^{\circ} \mathrm{C}$ for initial denaturation, followed by 34 cycles of $30 \mathrm{~s}$ at $92{ }^{\circ} \mathrm{C}, 30 \mathrm{~s}$ at $36{ }^{\circ} \mathrm{C}$ and $1.5 \mathrm{~min}$ at $72{ }^{\circ} \mathrm{C}$, and a final extension step of $5 \mathrm{~min}$ at $72{ }^{\circ} \mathrm{C}$. The PCR products were separated on $2 \%$ agarose gels in $1 \times$ Tris-Borate-EDTA buffer with 100 bp DNA ladders (QIAGEN, Hombrechtikon, Switzerland) as size standard. Clear and distinct bands were scored after 
staining the gels with ethidium bromide. Size range of PCR fragments was between 250 and 1,900 bp. All analysed accessions yielded readable RAPD profiles. Repeatability of the banding patterns in eleven replicated accessions was $96 \%$, with 16 out of 374 bands mismatching.

RAPD gel pictures were coded as a zero/one matrix, and we selected 31 reliable (polymorphic and monomorphic) loci. Including monomorphic bands is important when assessing indices such as genetic differentiation (Nei 1973). GenAlEx v6.5 (Peakall and Smouse 2012) was used to estimate the unbiased molecular partitioning of differentiation (AMOVA) among regions $\left[\Phi_{\mathrm{RT}}^{\prime}\right.$, with $\Phi^{\prime}$ being an analogue of $F^{\prime}$; Meirmans (2006)] and among populations within regions $\left(\Phi_{\mathrm{SR}}^{\prime}\right)$, using jackknifing over populations to obtain $95 \%$ confidence intervals. We also assessed sensitivity of $\Phi^{\prime}$ estimates to the selection of loci by jackknifing over loci.

$Q-\Phi^{\prime}$ comparison

We compared RAPD marker differentiation with trait differentiation to infer past selection (i.e. $Q_{\mathrm{ST}}-F_{\mathrm{ST}}$ comparisons; Merilä and Crnokrak 2001). For each trait, differentiation among regions, $Q_{\mathrm{RT}}$, and among populations within regions, $Q_{\mathrm{SR}}$, was computed based on variance components obtained from a random-effects model including competition, region, population and seed family. Under the assumption that the progenies of a maternal plant were half-sibs, we used the formulae $Q_{\mathrm{RT}}=V_{\mathrm{REG}} /\left(8 V_{\mathrm{FAM}}+V_{\mathrm{REG}}\right)$ and $Q_{\mathrm{SR}}=V_{\mathrm{POP}} /$ $\left(8 V_{\mathrm{FAM}}+V_{\mathrm{POP}}\right)$, where $V_{\mathrm{REG}}, V_{\mathrm{POP}}$, and $V_{\mathrm{FAM}}$ correspond to the variance among regions, among populations and among seed families within populations, respectively, to obtain indices of among- and within-region differentiation (Petit et al. 2001; Volis et al. 2005). When comparing trait differentiation with genetic differentiation $\left(\Phi^{\prime}\right)$ theory predicts $Q=\Phi^{\prime}$ if a trait differentiated neutrally, while $Q>\Phi^{\prime}$ is predicted under diversifying selection, and $Q<\Phi^{\prime}$ is predicted under unifying selection (Merilä and Crnokrak 2001; Scheepens et al. 2010).

Selection analysis and trait-trait correlations

To investigate current phenotypic selection pressures on the common-garden plants we applied Lande-Arnold's selection analysis (Lande and Arnold 1983; Haggerty and Galloway 2011). Selection differentials (i.e. direct and indirect selection combined) and linear selection gradients (i.e. direct selection) were calculated for each region separately for the following traits: biomass, number of leaves, number of stems, stem length, flowering start and flowering end. VIFs of this set of traits generally fell below 5, indicating acceptable multicollinearity. Only the trait of flowering end for the Scandinavian populations showed a VIF of 5.9, which we ignored. Number of capsules was used as a proxy for fitness, and relative fitness was calculated per region. We included populations as a factor into the selection gradient analyses to account for lack of independence among respective group members, but seed family was omitted due to low sample size.

We performed multiple trait-trait correlations per region on this reduced set of traits, using Holm-Bonferroni correction for multiple testing, in order to assess whether genetic constraints may hamper evolution of traits under climate change. Correlations were tested on scaled and centered phenotypic values using the function corr.test in R-package psych version 1.3.10 (Revelle 2013). 


\section{Results}

Phenotypic differentiation

In total 548 plants flowered (69\% of plants were alive at the July measurement), and the percentage of flowering plants decreased towards higher latitude and higher elevation (region effect; Tables 1, 2). At the end of the experiment 294 plants $(29 \%)$ had died, and 74 of these $(25 \%)$ had flowered. Survival likewise showed a strong decrease with higher latitude and higher elevation of origin (Tables 1,2).

The start of flowering ranged from 2nd June to 20th September with a peak of plants starting to flower at 26th July. The flowering period lasted until 23rd October and flowering duration of plants lasted for $38 \pm 16$ days (mean \pm SD). The mean flowering duration of Scandinavian plants was significantly shorter than those from The Netherlands and Central Europe (Tables 1, 2; Fig. 2a). The Scandinavian plants showed a delayed start and end of flowering compared to lower latitudes, whereas Alpine plants showed an advanced start and end of flowering compared to Central European plants (Fig. 3; Table S3 in the Appendix). The Dutch and Central European plants had approximately four times higher number of capsules and two times higher above-ground biomass compared to Scandinavian and Alpine plants (Table 1; Fig. 2b, c). Length and number of flowering stems decreased

Table 1 Phenotypic differentiation in C. rotundifolia shown as mean \pm SE per region and per competition treatment

\begin{tabular}{|c|c|c|c|c|}
\hline & $\begin{array}{l}\text { Flowering }(\%) \\
n=839\end{array}$ & $\begin{array}{l}\text { Flowering duration (days) } \\
n=586\end{array}$ & $\begin{array}{l}\text { Number of leaves } \\
n=760\end{array}$ & $\begin{array}{l}\text { Stem length }(\mathrm{cm}) \\
n=728\end{array}$ \\
\hline \multicolumn{5}{|l|}{ Region } \\
\hline $\mathrm{SC}$ & $28.9 \pm 4.9^{\mathrm{a}}$ & $30.8 \pm 2.2^{\mathrm{a}}$ & $15.9 \pm 2.8$ & $4.9 \pm 0.5^{\mathrm{a}}$ \\
\hline NL & $70.9 \pm 7.2^{\mathrm{b}}$ & $38.2 \pm 2.0^{\mathrm{b}}$ & $10.3 \pm 1.3$ & $15.5 \pm 3.2^{\mathrm{b}}$ \\
\hline $\mathrm{CE}$ & $85.3 \pm 6.0^{\mathrm{b}}$ & $39.2 \pm 1.3^{\mathrm{b}}$ & $10.9 \pm 1.6$ & $16.9 \pm 2.2^{\mathrm{b}}$ \\
\hline $\mathrm{AL}$ & $68.0 \pm 4.7^{\mathrm{b}}$ & $33.8 \pm 1.5^{\mathrm{ab}}$ & $12.3 \pm 2.4$ & $13.4 \pm 1.4^{\mathrm{b}}$ \\
\hline Control & $68.3 \pm 6.0^{\mathrm{a}}$ & $37.3 \pm 1.4^{\mathrm{a}}$ & $13.4 \pm 1.5$ & $13.3 \pm 1.6^{\mathrm{a}}$ \\
\hline Competition & $60.6 \pm 5.8^{\mathrm{b}}$ & $33.5 \pm 1.5^{\mathrm{b}}$ & $12.2 \pm 1.2$ & $12.0 \pm 1.4^{\mathrm{b}}$ \\
\hline & $\begin{array}{l}\text { Number of } \\
\text { capsules } n=586\end{array}$ & $\begin{array}{l}\text { Number of stems } \\
n=637\end{array}$ & $\begin{array}{l}\text { Above-ground biomass }(\mathrm{g}) \\
n=783\end{array}$ & $\begin{array}{l}\text { Survival }(\%) \\
n=1,064\end{array}$ \\
\hline \multicolumn{5}{|l|}{ Region } \\
\hline SC & $2.0 \pm 0.8^{\mathrm{a}}$ & $2.0 \pm 0.2^{\mathrm{a}}$ & $0.25 \pm 0.03^{\mathrm{a}}$ & $50.7 \pm 6.9^{\mathrm{a}}$ \\
\hline NL & $9.9 \pm 1.6^{\mathrm{b}}$ & $3.5 \pm 0.3^{\mathrm{b}}$ & $0.57 \pm 0.07^{b}$ & $71.7 \pm 7.8^{\mathrm{a}}$ \\
\hline $\mathrm{CE}$ & $12.4 \pm 2.5^{\mathrm{b}}$ & $3.2 \pm 0.4^{\mathrm{b}}$ & $0.67 \pm 0.08^{\mathrm{b}}$ & $96.1 \pm 2.4^{\mathrm{b}}$ \\
\hline $\mathrm{AL}$ & $3.2 \pm 1.1^{\mathrm{a}}$ & $2.8 \pm 0.2^{\mathrm{ab}}$ & $0.30 \pm 0.02^{\mathrm{a}}$ & $66.4 \pm 5.8^{\mathrm{a}}$ \\
\hline Control & $8.8 \pm 1.8^{\mathrm{a}}$ & $3.3 \pm 0.2^{\mathrm{a}}$ & $0.54 \pm 0.06^{\mathrm{a}}$ & $66.8 \pm 5.7^{\mathrm{a}}$ \\
\hline Competition & $5.3 \pm 0.9^{b}$ & $2.6 \pm 0.2^{\mathrm{b}}$ & $0.39 \pm 0.04^{\mathrm{b}}$ & $76.1 \pm 4.4^{\mathrm{b}}$ \\
\hline
\end{tabular}

Control: C. rotundifolia alone; Competition: C. rotundifolia growing with B. erectus

Mean \pm SD are based on population means, which in turn are based on seed family means

Different superscript letters indicate significant differences in means $(\alpha=0.05)$ among regions using Tukey's HSD and between competition treatments based on the model results (Table 2)

$S C$ Scandinavia, $N L$ The Netherlands, $C E$ Central Europe, $A L$ Swiss Alps 
Table 2 Results of hierarchical generalised mixed-effects models analysing the effects of competition, region, population and seed family on eight phenotypic traits of $C$. rotundifolia

\begin{tabular}{lllllc}
\hline & $d f$ & Flowering & Flowering duration & Number of leaves & Stem length \\
\hline Competition & 1 & $3.2^{*}$ & $5.6^{*}$ & 0.0 & $9.9^{* *}$ \\
Region & 3 & $12.5^{* *}$ & $3.8^{*}$ & 1.2 & $7.2^{* *}$ \\
Population & 1 & 3.0 & 0.5 & 3.4 & $21.5^{* * *}$ \\
Seed family & 1 & $5.0^{*}$ & 1.7 & $31.1^{* * *}$ & $32.1^{* * *}$ \\
Comp $\times$ Reg & 3 & 1.2 & 1.2 & 2.2 & $5.2^{*}$ \\
Comp $\times$ Pop & 1 & 0.5 & - & 0.2 & 0.0 \\
Comp $\times$ Sf & 1 & 0.0 & $5.2^{*}$ & 1.7 & 0.0 \\
Max res $d f$ & & 777 & 536 & 703 & 675 \\
\hline & $d f$ & Number of capsules & Number of stems & Above-ground biomass & Survival \\
\hline Competition & 1 & $7.8^{*}$ & $21.0^{* * *}$ & $34.6^{* * *}$ & $13.9^{* * *}$ \\
Region & 3 & $9.4^{* * *}$ & $4.6^{*}$ & $12.3^{* * *}$ & $10.6^{* * *}$ \\
Population & 1 & 2.6 & $4.3^{*}$ & $8.3^{* *}$ & 1.7 \\
Seed family & 1 & $7.4^{* *}$ & $15.2^{* * *}$ & $30.6^{* * *}$ & $39.9^{* *}$ \\
Comp $\times$ Reg & 3 & $3.7^{*}$ & 1.2 & 2.0 & 2.4 \\
Comp $\times$ Pop & 1 & 0.1 & 0.2 & 1.7 & 0.0 \\
Comp $\times$ Sf & 1 & $9.0^{* *}$ & 0.0 & 2.7 & 0.0 \\
Max res $d f$ & & 562 & 586 & 728 & 997 \\
\hline
\end{tabular}

$F$ and $\chi^{2}$ values for fixed and random factors respectively are shown with their significance values

Comp Competition, Reg Region, Pop Population, Sf Seed family, Max res $d f$ Maximum residual degrees of freedom

* $P=0.05-0.01 ; * * P=0.01-0.001 ; * * * P<0.001$

with latitude and elevation (Tables 1,2). Populations within regions were significantly different in length and number of stems as well as in above-ground biomass (Table 2). Seed families within populations were always significantly different except in flowering duration, indicating ample genetic diversity within populations.

\section{Trait-environment correlations}

Various traits showed significant correlations with latitude or elevation of origin (Table 3). In the latitude dataset flowering duration, stem length, number of capsules and survival correlated with latitude. All these traits also correlated with temperature range and precipitation sum, and only survival correlated with summer temperature. In the elevation dataset survival correlated with all environmental variables, whereas flowering duration only correlated with elevation.

The competition treatment had a significant effect on seven out of eight traits (Table 2). As could be expected, competition had a negative effect on trait values, except for survival data, which, surprisingly, showed that plants growing with competitors had a higher chance of survival in the common-garden experiment (Table 1). Competition interacted with regional origin for stem length and number of capsules, and with seed family for flowering duration and number of capsules (Table 2). 
(a)
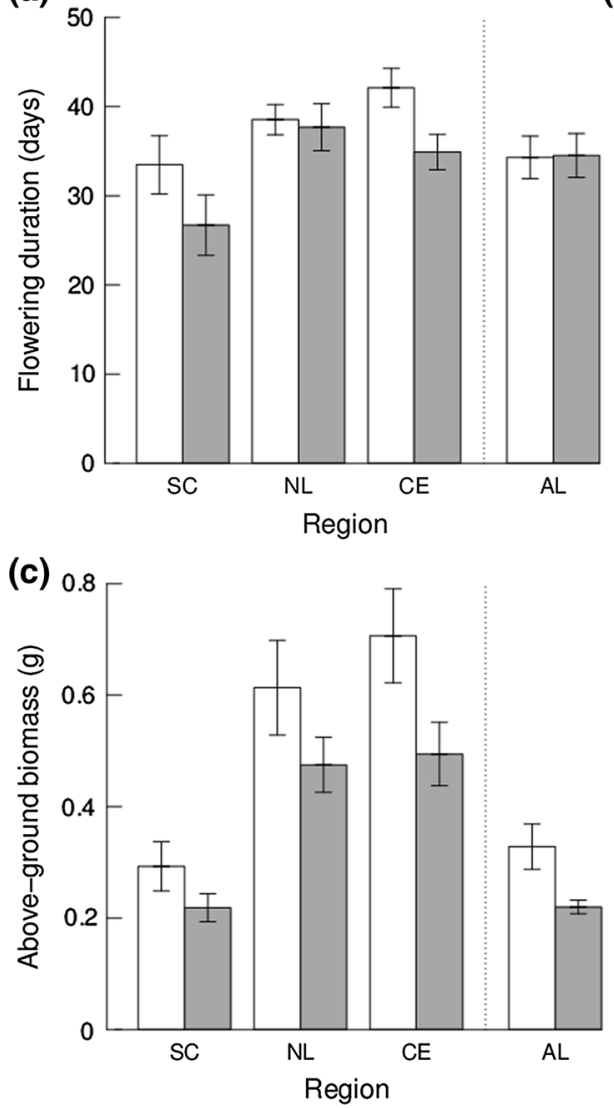

(b)

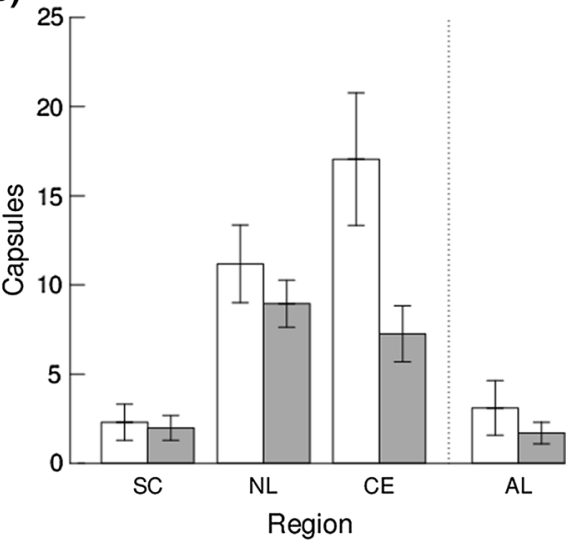

Fig. 2 Differentiation between regions $S C$ Scandinavia, $N L$ The Netherlands, $C E$ Central Europe and $A L$ Swiss Alps in a flowering duration, $\mathbf{b}$ number of capsules and $\mathbf{c}$ above-ground biomass of $C$. rotundifolia grown in a common garden in Basel, Switzerland. Mean \pm SE are indicated. White bars: plants growing without competitor; grey bars: plants growing with B. erectus as competitor. The dotted vertical line separates the regions that are situated on a latitudinal gradient (left) and the high-elevation region (right)

\section{Past selection pressures}

Differentiation among regions, $\Phi_{\mathrm{RT}}^{\prime}$, was 0.069 (confidence interval based on jackknifing over populations: $0.060-0.078$ ) and among populations within regions, $\Phi_{\text {SR }}^{\prime}$, was 0.351 (0.345-0.357). These estimates were only weakly influenced by locus selection [jackknifing over loci: mean (95\% confidence interval); $\Phi_{\mathrm{RT}}^{\prime}=0.069 \quad(0.066-0.072)$; $\left.\Phi_{\mathrm{SR}}^{\prime}=0.352(0.347-0.356)\right]$. Trait differentiation among regions $\left(Q_{\mathrm{RT}}\right)$ exceeded molecular marker differentiation among regions $\left(\Phi_{\mathrm{RT}}^{\prime}\right)$ for flowering, stem length, number of capsules, above-ground biomass and survival, indicating diversifying selection (Table 4). Flowering duration, number of leaves and number of stems had lower $Q_{\mathrm{RT}}$ than $\Phi_{\mathrm{RT}}^{\prime}$, indicating unifying selection. For all traits, differentiation among populations within 
(a)

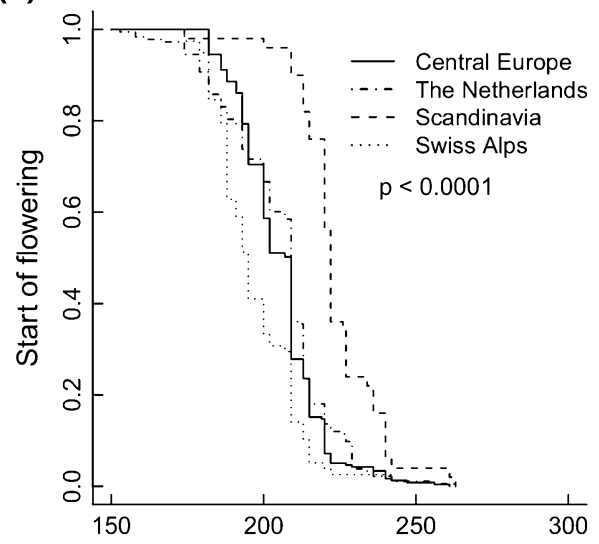

(c)

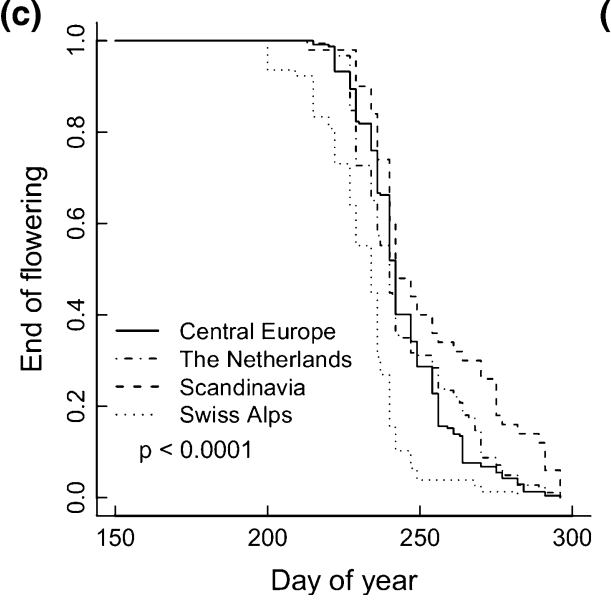

(b)

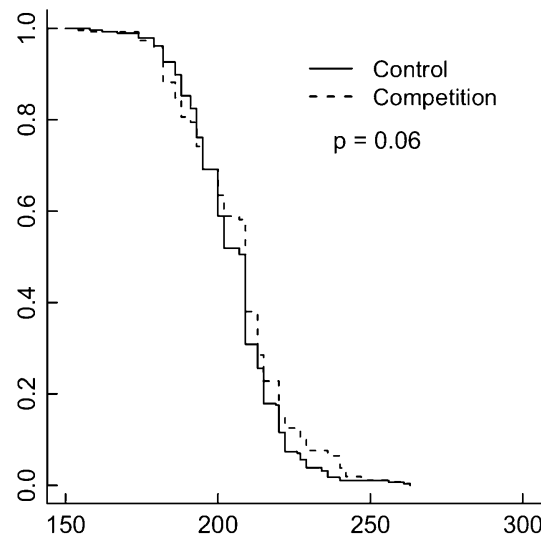

(d)

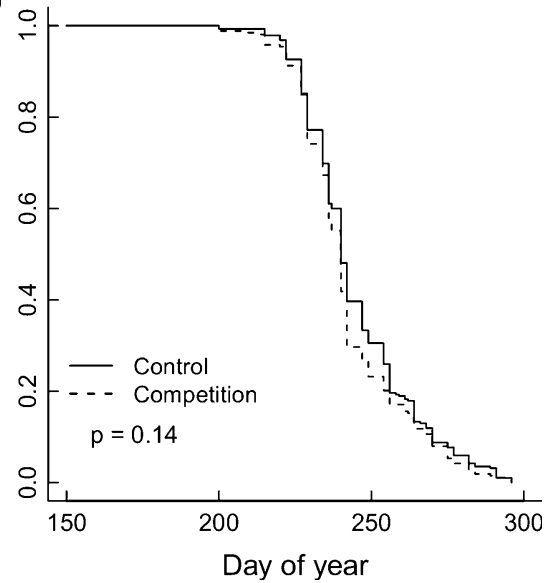

Fig. 3 Kaplan-Meier non-parametric survival curves and $P$ values based on the Log-Rank test comparing start of flowering (top panels) and end of flowering (bottom panels) among regions (left panels) and between the competition treatments (right panels) in C. rotundifolia

regions $\left(Q_{\mathrm{SR}}\right)$ was smaller than molecular marker differentiation attributed among populations within regions $\left(\Phi_{\text {SR }}^{\prime}\right)$, indicating unifying selection.

Selection analysis and trait-trait correlations

Selection analysis revealed positive and negative selection gradients $(\beta)$ and differentials (S) among all traits and regions (Table 5). Biomass, number of stems and stem length were under strong positive selection. Selection for a longer flowering duration was found in Central European and Dutch populations, indicated by a negative selection gradient and differential on flowering start (Central Europe) and a positive selection gradient and differential on flowering end (Central Europe and The Netherlands). 
Table 3 Pearson's correlation coefficients and $P$ values for correlations between phenotypic traits of C. rotundifolia and the following factors: (a) latitude, for SC, NL and CE regions; (b) elevation, for CE and AL regions; (for both sets of regions) temperature mean, temperature range and precipitation for the months June-August

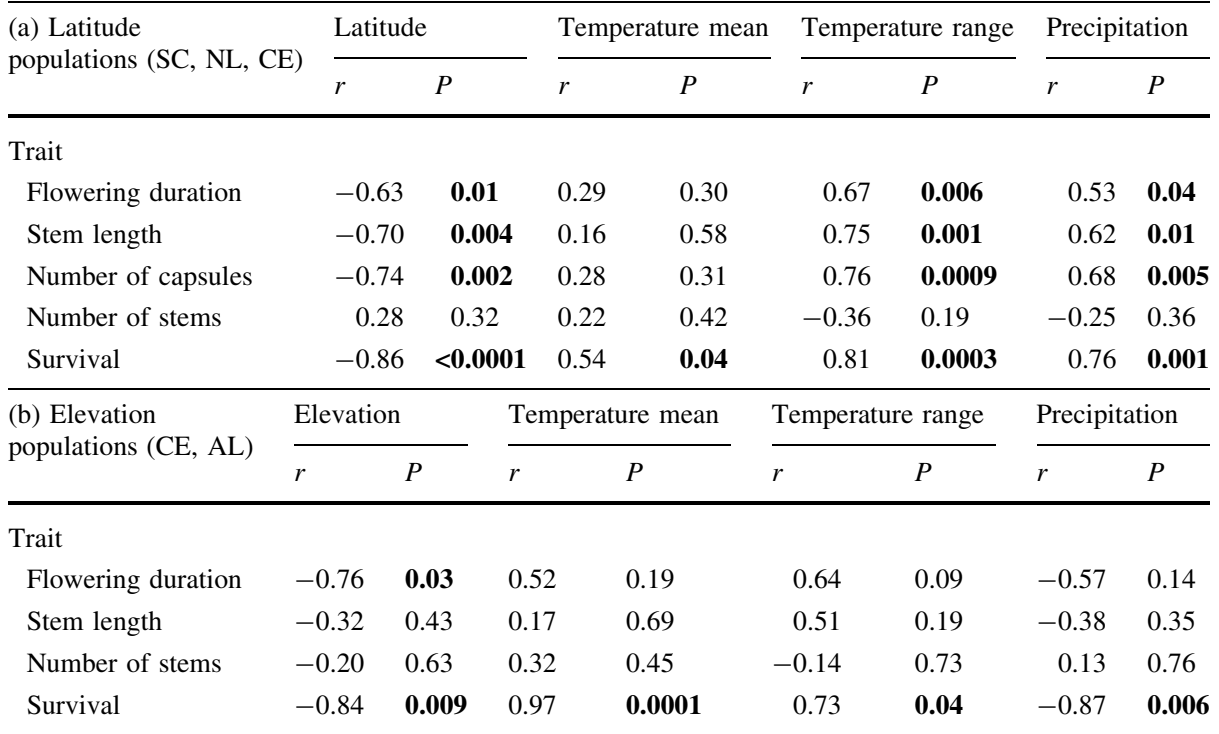

Results for two subsets of all measured traits are shown after trait selection based on an analysis of multicollinearity between traits

$S C$ Scandinavia, $N L$ The Netherlands, $C E$ Central Europe, $A L$ Swiss Alps

Significant $P$ values are in bold

Table 4 Quantitative phenotypic differentiation among regions $\left(Q_{\mathrm{RT}}\right)$ and among populations within regions $\left(Q_{\mathrm{SR}}\right)$ for eight phenotypic traits of $C$. rotundifolia shown as means (95\% confidence intervals). The greater- and smaller-then signs indicate the comparison between the values and the results from the marker analysis: molecular differentiation among regions $\left(\Phi_{\mathrm{RT}}^{\prime}\right)$ and and among populations within regions $\left(\Phi_{\mathrm{SR}}^{\prime}\right)$

\begin{tabular}{lllll}
\hline & $Q_{\mathrm{RT}}$ & $Q_{\mathrm{RT}}-\Phi_{\mathrm{RT}}^{\prime}$ & $Q_{\mathrm{SR}}$ & $Q_{\mathrm{SR}}-\Phi_{\mathrm{SR}}^{\prime}$ \\
\hline Flowering & $0.317(0.295-0.339)$ & $>$ & $0.147(0.128-0.167)$ & $<$ \\
Flowering duration & $0.049(0.045-0.053)$ & $<$ & $0.008(0.006-0.011)$ & $<$ \\
Number of leaves & $0.002(0.000-0.004)$ & $<$ & $0.033(0.028-0.038)$ & $<$ \\
Stem length & $0.157(0.142-0.172)$ & $>$ & $0.181(0.105-0.131)$ & $<$ \\
Number of capsules & $0.159(0.143-0.176)$ & $>$ & $0.032(0.025-0.039)$ & $<$ \\
Number of stems & $0.035(0.028-0.043)$ & $<$ & $0.026(0.022-0.031)$ & $<$ \\
Above-ground biomass & $0.182(0.168-0.197)$ & $>$ & $0.049(0.042-0.056)$ & $<$ \\
Survival & $0.308(0.248-0.368)$ & $>$ & $0.107(0.071-0.143)$ & $<$
\end{tabular}

$\Phi_{\mathrm{RT}}^{\prime}=0.069(0.060-0.078)$ and $\Phi_{\mathrm{SR}}^{\prime}=0.351(0.345-0.357)$

The $95 \%$ confidence intervals for $Q$ and $\Phi^{\prime}$ were based on jackknifing over populations

Trait-trait correlation analysis revealed negative as well as positive correlations among traits in plants from the four regions (Table S4 in the appendix), and all correlations were either neutral or favourable with respect to observed selection pressures in the common- 
garden environment (Table 5) except for a positive correlation between flowering start and flowering end in Central Europe (Table S4). This correlation may potentially hamper the above-mentioned selection for earlier flowering start and later flowering end.

\section{Discussion}

This study revealed regional genetic differentiation in C. rotundifolia across Europe for the majority of the investigated phenotypic traits (Table 2; Table S3). Most traits indicated a clinal pattern of phenotypic differentiation along the latitudinal gradient (Table 3), suggesting adaptation to gradual climatic conditions. Along the elevation gradient a clinal pattern was less conspicuous, with only survival strongly correlating with environmental variables. All traits implied adaptation to the current local conditions by showing evidence for selection in the past (Table 4). For most trait-trait comparisons no genetic constraints antagonistic to the directions of selection on the respective traits were found. Start and end of flowering in plants from Central Europe showed an antagonistic positive correlation (Table 5; Table S4).

\section{Differentiation in flowering phenology}

To complete the reproductive cycle in time during short growing seasons at high latitude and high elevation, shorter flowering duration and early onset of flowering after start of the growing season is expected (Turesson 1925, 1930; Weber and Schmid 1998; Olsson and Ågren 2002; Montague et al. 2008). Vice versa, plants from southern regions and lowlands would show prolonged flowering duration and, to avoid late frosts and to benefit from longer vegetative growth, a later onset of flowering. In line with these expectations the phenological traits in $C$. rotundifolia revealed a genetically based clinal variation, with a

Table 5 Selection analysis showing selection differentials $(\mathrm{S})$ and gradients $(\beta)$ for a set of selected traits of C. rotundifolia

\begin{tabular}{|c|c|c|c|c|c|c|}
\hline \multirow[t]{2}{*}{ Region } & \multicolumn{2}{|c|}{ Above-ground biomass } & \multicolumn{2}{|c|}{ Number of leaves } & \multicolumn{2}{|c|}{ Number of stems } \\
\hline & $\mathrm{S}$ & $\beta$ & $\mathrm{S}$ & $\beta$ & $\mathrm{S}$ & $\beta$ \\
\hline $\mathrm{SC}$ & $1.690 * * *$ & $2.598 * * *$ & -0.179 & -0.560 & $1.465 * * *$ & -0.179 \\
\hline NL & $0.748 * * *$ & $0.593 * * *$ & 0.090 & $-0.115^{*}$ & $0.515 * * *$ & $0.248 * * *$ \\
\hline $\mathrm{CE}$ & $0.807 * * *$ & $0.692 * * *$ & -0.049 & 0.002 & $0.515 * * *$ & 0.058 \\
\hline \multirow[t]{3}{*}{$\mathrm{AL}$} & $1.503 * * *$ & $1.161 * * *$ & 0.263 & $0.394 *$ & $0.852 * * *$ & 0.079 \\
\hline & \multicolumn{2}{|l|}{ Stem length } & \multicolumn{2}{|c|}{ Flowering start } & \multicolumn{2}{|c|}{ Flowering end } \\
\hline & $\mathrm{S}$ & $\beta$ & $\mathrm{S}$ & $\beta$ & $\mathrm{S}$ & $\beta$ \\
\hline $\mathrm{SC}$ & $1.304 * * *$ & -0.416 & -0.300 & -0.222 & 0.190 & 0.568 \\
\hline NL & $0.287 * *$ & $0.211 * *$ & 0.013 & 0.030 & $0.188^{*}$ & 0.006 \\
\hline CE & $0.398 * * *$ & 0.075 & $-0.290 * * *$ & $-0.141 * *$ & $0.169 * *$ & $0.107 *$ \\
\hline $\mathrm{AL}$ & $0.859 * * *$ & 0.168 & 0.150 & $0.593 *$ & 0.133 & -0.432 \\
\hline
\end{tabular}

$S C$ Scandinavia, $N L$ The Netherlands, $C E$ Central Europe, $A L$ Swiss Alps

* $P=0.05-0.01 ; * * P=0.01-0.001 ; * * * P<0.001$ 
decrease in flowering duration with increasing latitude and elevation. Moreover, plants from Alpine populations of $C$. rotundifolia showed an advanced flowering period in the common garden, in line with findings of Turesson's (1925). In contrast, the Scandinavian plants showed a relatively delayed flowering period. Since photoperiod is strongly determined by latitude but hardly by elevation, these results suggest that photoperiodicity has a strong effect on flowering initiation of $C$. rotundifolia.

\section{Differentiation in fitness-related traits}

In the common garden the Central European populations were the ones with highest fitness. This suggests a home-site effect since these populations originated from locations with a distance to the common garden of less than $20 \mathrm{~km}$. Such patterns of home-site advantage have often been found in similar studies (e.g. Joshi et al. 2001; Vergeer and Kunin 2013). Survival, biomass, reproductive rate and output as well as stem length showed a decrease with higher latitude. Similar latitudinal patterns in growth have been observed in C. rotundifolia by Turesson (1925) and in other species, such as Arabidopsis thaliana (Li et al. 1998) and L. salicaria (Olsson and Ågren 2002). Furthermore, decreasing biomass accumulation with increasing latitude and elevation of origin has been a general finding too (e.g. Li et al. 1998; Monty and Mahy 2009; Scheepens et al. 2013). Lower trait values in plants originating from higher latitude and higher elevation may be explained by two not mutually exclusive hypotheses: (1) experimental plants reflected the genetic differentiation associated with their site of origin (Joshi et al. 2001; Olsson and Ågren 2002; Volis et al. 2005; Monty and Mahy 2009); (2) the plants responded to the common-garden conditions with passive plasticity, which resulted in maladaptation (Ghalambor et al. 2007; Scheepens and Stöcklin 2013). Although the maladaptive plasticity to the common-garden environment cannot be disproven, the here observed clinal pattern in resource investment strategy support the first hypothesis.

Competition decreased fitness-related traits (flowering rate, number and length of stems, capsule production and biomass) as shown in numerous other studies (e.g. Pluess and Stöcklin 2005). Partzsch and Bachmann (2011) found a similar strong decrease in fecundity in Campanula glomerata in a greenhouse experiment with two competitive grass species. However, increased survival under competition was surprising and is probably an indirect consequence of a relatively higher investment in vegetative growth of the plants competing with B. erectus.

\section{Trait-environment correlations}

To find out which environmental factors influence the differentiation of traits, we correlated historical climate data of the accessions' origins with the tested traits. Only survival correlated with the temperature mean of sample origin, while temperature range and precipitation sum correlated with many traits. This suggests that adaptation to local temperature fluctuations and amount of precipitation is more important for growth and reproduction than adaptation to temperature mean.

If we assume that larger trait values reflect higher fitness, these trait-environment correlations could be a result of home-site advantage in plants from Central European populations through adaptation to large diurnal temperature changes and precipitation means. For the correlation between trait values and precipitation we would like to emphasise that these findings hold for the selection of $C$. rotundifolia accessions in this experiment, which were originating from moderately wet locations; accessions from drier 
environments (e.g. southern France) may well show different relationships to precipitation of origin.

Along the elevation gradient, survival correlated well with environmental variables, but the elevation cline in flowering duration could not be explained. This suggests that other environmental factors, such as soil nutrients or snow-melt patterns, may drive clinal differentiation in flowering duration. Stem length and number of stems showed no correlations with any environmental factor including elevation, and therefore these traits may be governed by adaptation to small-scale heterogeneity or by genetic drift (Linhart and Grant 1996).

\section{Past selection pressures}

Past selection pressure was observed in all traits $\left(Q-\Phi^{\prime}\right.$ comparisons). Most traits diverged under selection among regions, whereas traits showed only restricted differentiation (i.e. unifying selection) within regions. Stronger environmental differentiation among than within regions can be expected and is suggested by higher average $Q$ values among regions irrespective of molecular differentiation. Comparable results have been observed in Hordeum spontaneum (Volis et al. 2005), but the opposite has also been found, for instance in Quercus suber (Ramirez-Valiente et al. 2009).

Depending on the scale of environmental heterogeneity, past diversifying selection may occur among populations within regions (Volis et al. 2005). The unifying selection among populations within regions in our study suggests either that environmental conditions are comparable within the sampled regions which selects against trait divergence, or that past neutral differentiation exceeded trait differentiation among locally adapted populations. The first explanation seems unlikely given the geographic distances among populations within regions, which should lead to local adaptation; the second explanation seems thus more likely and may hold despite recent adaptation to changing climatic conditions. This is because, at the within-region scale, climate change is likely approximately uniform and therefore would select for unidirectional changes in phenological traits. Therefore it would not appear as trait differentiation among populations within those regions.

We expected flowering duration to show diversifying selection among regions since observations of flowering duration showed regional differentiation in the common garden. Instead we found past unifying selection which we can only explain by a significant divergence in flowering duration across latitude that has been achieved with limited genetic differentiation below the neutral rate of differentiation.

Methods for $Q_{\mathrm{ST}}-F_{\mathrm{ST}}$ comparisons as well as the reliability of both indices are debated (Whitlock 2008; Edelaar et al. 2011). In our study, the advantage of using RAPD markers instead of microsatellite markers is their presumed lower mutation rates, comparable to those of phenotypic traits, resulting in more trustworthy $\Phi^{\prime}$ values (Edelaar et al. 2011). Despite this advantage, some critical points remain. As in many other common-garden studies, we assume that the phenotypic variation is the result of additive gene action only, but we cannot completely rule out maternal, epistatic, dominance or epigenetic effects (Goudet and Büchi 2006; Whitlock 2008). Our results should therefore be interpreted with caution and only taken as complementary means to detect adaptive patterns.

Maternal effects and experimental conditions

Since we worked with plants from field-collected seeds, the phenotypic expression observed in the common garden could be influenced by the maternal environment. However, 
Ouborg et al. (1991) showed for two perennial, outcrossing grassland herbs that maternal effects were only present at the seedling and juvenile stages, whereas traits measured during the flowering stage were unaffected. Similar observations of decreasing influence of the maternal environment over time are more commonly observed (Bischoff and MüllerSchärer 2010; Scheepens et al. 2013). Since we measured mature, mostly flowering plants in this study we assume that the influence of the maternal environment is negligible. Moreover, it may be assumed that variation explained by genetic differentiation across large latitudinal and elevation ranges is much stronger than variation explained by the maternal environment (Bischoff and Müller-Schärer 2010).

The location of the common garden corresponded to a warmer climate for accessions of C. rotundifolia from higher latitude and elevation. By situating the experimental garden outside and by adding a competition treatment, the experimental plants experienced a semi-natural environment. Still, we are aware of the unrealistic effects of plants being pregrown in the greenhouse and then grown in pots with ample watering. However, in this way we provided a controlled environment which focussed on temperature manipulation for plants from higher latitudes and elevations.

Predictions for future adaptation

Overall we observed strong clinal patterns with latitude and elevation in most investigated traits (except in number of leaves), suggesting current adaptation of plants to their habitat and the need for these traits to adapt to future climate change. Especially adaptation of phenological traits to changing growing season lengths represents a challenge for plants. Under a warming climate plants should postpone their flowering and increase flowering duration to escape late frosts and to maximize fecundity, by investing more in vegetative growth before flowering (Montague et al. 2008) and producing more seeds over a longer flowering period (Olsson and Ågren 2002). In line with these expectations flowering duration seemed adapted to the growing season length of origin. Past diversifying selection was likewise found among regions for most investigated traits except for flowering duration and number of leaves and stems. The fact that flowering duration showed unifying selection among regions and only limited divergence is unexpected but does not per se contradict local adaptation to the region of origin.

Since the common garden simulates warmer conditions of the future for Scandinavian, Dutch and even Central European plants (IPCC 2013), the selection pressures may indicate whether genetic variation is available for selection to act on and in which direction selection will act. A generally enhanced growth, favoured by the warmer common-garden conditions, was observed through strong positive selection for biomass, number of stems and stem length in plants from all regions. This observation fits well with larger stature and higher biomass in plants from warmer regions in this and other studies (e.g. Olsson and Ågren 2002).

When combining selection pressures for flowering start and end, selection for increased flowering duration was observed in plants from the home-site region (Central Europe) and from The Netherlands, whereas plants from the Swiss Alps experienced direct selection for later flowering, while plants from Scandinavia did not respond to selection at all. This unexpected regional pattern in selection on flowering duration could be explained by the fact that plants from Scandinavia and-especially - the Swiss Alps experienced commongarden conditions so different from their origin that phenotypic responses diverged randomly among plants, leading to high phenotypic trait variance and absence of correlations with fitness (Ghalambor et al. 2007). Another possibility may be that, in contrast to plants 
from The Netherlands and Central Europe, plants from Scandinavia and the Swiss Alps are too far from their fitness optimum so that selection is weak as it does not lead to significant fitness increases (Anderson et al. 2012).

Importantly, selection analyses and trait-trait correlations showed that most traits can respond to selection under a warmer climate. Only the response to selection on flowering duration was erratic for plants from high latitude and elevation and is potentially hampered by a correlation between flowering start and end. However, given that the climate change we simulated may only happen over multiple decennia and not, as in our treatment, at once, these populations may in reality have time to respond to selection appropriately. Moreover, the correlation between flowering start and flowering end may not be so strong as to hinder evolutionary changes in this trait. Concluding, our results suggest that $C$. rotundifolia populations across a wide geographic range in Europe are currently adapted to their local climate and may well be able to adapt to future climate change.

Acknowledgments We thank Hans Henrik Bruun, Paul Geense and Collette Coumans who helped with sampling. We are also grateful to biology students and staff of the botanical garden in Basel who assisted the common-garden experiment. Xavier Picó and an anonymous reviewer are thanked for their helpful comments on the manuscript. Permission to sample seed and leaf material of $C$. rotundifolia in The Netherlands was kindly given by the Ministry of LNV, The Netherlands (FF/75A/2008/023). This study was financially supported by a grant from the Prins Bernhard Cultuurfonds to JFS (2007).

\section{References}

Anderson JT, Inouye DW, McKinney AM, Colautti RI, Mitchell-Olds T (2012) Phenotypic plasticity and adaptive evolution contribute to advancing flowering phenology in response to climate change. Proc $\mathrm{R}$ Soc B 279:3843-3852

Bates D, Maechler M, Bolker B, Walker S (2014) lme4: linear mixed-effects models using Eigen and S4. http://cran.r-project.org/web/packages/lme4/index.html

Bingham R, Orthner AR (1998) Efficient pollination of alpine plants. Nature 391:238-239

Bischoff A, Müller-Schärer H (2010) Testing population differentiation in plant species-How important are environmental maternal effects. Oikos 119:445-454

Blionis GJ, Halley J, Vokou D (2001) Flowering phenology of Campanula on Mt Olympos, Greece. Ecography 24:696-706

Bretz F, Hothorn T, Westfall P (2010) Multiple comparisons using R. CRC Press, Boca Raton. http://cran.rproject.org/web/packages/multcomp/index.html

Briggs D, Walters S (1997) Plant variation and evolution, 3rd edn. Cambridge University Press, Cambridge

Clausen J, Keck D, Hiesey W (1947) Heredity of geographically and ecologically isolated races. Am Nat 81:114-133

Clevering O, Brix H, Lukavska J (2001) Geographic variation in growth responses in Phragmites australis. Aquat Bot 69:89-108

Davis MB, Shaw RG (2001) Range shifts and adaptive responses to quaternary climate change. Science 292:673-679

Edelaar P, Burraco P, Gomez-Mestre I (2011) Comparisons between $Q_{\mathrm{ST}}$ and $F_{\mathrm{ST}}-$ How wrong have we been? Mol Ecol 20:4830-4839

Engelskjøn T, Lund L, Alsos I (2003) Twenty of the most thermophilous vascular plant species in Svalbard and their conservation state. Polar Res 22:317-339

Ghalambor CK, McKay JK, Carroll SP, Reznick DN (2007) Adaptive versus non-adaptive phenotypic plasticity and the potential for contemporary adaptation in new environments. Funct Ecol 21:394-407

Goudet J, Büchi L (2006) The effects of dominance, regular inbreeding and sampling design on $Q_{\mathrm{ST}}$, an estimator of population differentiation for quantitative traits. Genetics 176:1371-1374

Haggerty BP, Galloway LF (2011) Response of individual components of reproductive phenology to growing season length in a monocarpic herb. J Ecol 99:242-253

Heiberger RM, Holland B (2004) Statistical analysis and data display. Springer, Heidelberg. http://cran.rproject.org/package $=\mathrm{HH}$ 
Hijmans R, Cameron SE, Parra JL, Jones PG, Jarvis A (2005) Very high resolution interpolated climate surfaces for global land areas. Int J Climatol 25:1965-1978

Houle D (1992) Comparing evolvability and variability of quantitative traits. Genetics 130:195-204

IPCC (2013) Summary for policymakers. In: Stocker TF, D Qin, G-K Plattner, M Tignor, SK Allen, J Boschung, A Nauels, Y Xia, V Bex, PM Midgley (eds) Climate change 2013: the physical science basis. Contribution of Working Group I to the fifth assessment report of the Intergovernmental Panel on Climate Change. Cambridge University Press, Cambridge

Joshi J, Schmid B, Caldeira M, Dimitrakopoulos P, Good J, Harris R (2001) Local adaptation enhances performance of common plant species. Ecol Lett 4:536-544

Jump AS, Peñuelas J (2005) Running to stand still: adaptation and the response of plants to rapid climate change. Ecol Lett 8:1010-1020

Kuznetsova A, Brockhoff PB, Christensen RHB (2014) lmerTest: tests for random and fixed effects for linear mixed effect models (lmer objects for lme4 package). http://cran.r-project.org/web/packages/ lmerTest/index.html

Lande R, Arnold SJ (1983) The measurement of selection on correlated characters. Evolution 37:1210-1226

Lauber K, Wagner G (1998) Flora Helvetica. Paul Haupt, Bern

Li B, Suzuki J, Hara T (1998) Latitudinal variation in plant size and relative growth rate in Arabidopsis thaliana. Oecologia 115:293-301

Lindborg R, Cousins SAO, Eriksson O (2005) Plant species response to land use change-Campanula rotundifolia, Primula veris and Rhinanthus minor. Ecography 28:29-36

Linhart Y, Grant M (1996) Evolutionary significance of local genetic differentiation in plants. Annu Rev Ecol Syst 27:237-277

Meirmans PG (2006) Using the AMOVA framework to estimate a standardized genetic differentiation measure. Evolution 60:2399-2402

Merilä J, Crnokrak P (2001) Comparison of genetic differentiation at marker loci and quantitative traits. J Evol Biol 14:892-903

Montague H, Barrett S, Eckert C (2008) Re-establishment of clinal variation in flowering time among introduced populations of purple loosestrife (Lythrum salicaria, Lythraceae). J Evol Biol 21:234-245

Monty A, Mahy G (2009) Clinal differentiation during invasion: Senecio inaequidens (Asteraceae) along altitudinal gradients in Europe. Oecologia 159:305-315

Nei M (1973) Analysis of gene diversity in subdivided populations. Proc Natl Acad Sci USA 70:3321-3323

Nyman Y (1992) Pollination mechanism in six Campanula species (Campanulaceae). Plant Syst Evol 181:97-108

Olsson K, Agren J (2002) Latitudinal population differentiation in phenology, life history and flower morphology in the perennial herb Lythrum salicaria. J Evol Biol 15:983-996

Ouborg NJ, Van Treuren R, Van Damme JMM (1991) The significance of genetic erosion in the process of extinction. Oecologia 86:359-367

Ozenda P (1988) Die Vegetation der Alpen. Gustav Fischer, Stuttgart

Paccard A, Fruleux A, Willi Y (2014) Latitudinal variation and responses to drought in Arabidopsis lyrata. Oecologia 175:577-587

Partzsch M, Bachmann U (2011) Is Campanula glomerata threatened by competition from expanding grasses? Results from a 5-year pot-experiment. Plant Ecol 212:251-261

Peakall R, Smouse PE (2012) GenAlEx 6.5: genetic analysis in Excel. Population genetic software for teaching and research—an update. Bioinformatics 28:2537-2539

Petit C, Fréville H, Mignot A, Colas B, Riba M, Imbert E (2001) Gene flow and local adaptation in two endemic plant species. Biol Conserv 100:21-34

Pluess A, Stöcklin J (2005) The importance of population origin and environment on clonal and sexual reproduction in the alpine plant Geum reptans. Funct Ecol 19:228-237

R Development Core Team (2009) R: a language and environment for statistical computing. R Foundation for Statistical Computing, Vienna

Ramirez-Valiente J, Lorenzo Z, Soto A, Valladares F, Gil L, Aranda I (2009) Elucidating the role of genetic drift and natural selection in cork oak differentiation regarding drought tolerance. Mol Ecol $18: 3803-3815$

Revelle W (2013) psych: procedures for personality and psychological research. http://cran.r-project.org/ package $=$ psych

Scheepens JF, Stöcklin J (2013) Flowering phenology and reproductive fitness along a mountain slope: maladaptive responses to transplantation to a warmer climate in Campanula thyrsoides. Oecologia 171:679-691

Scheepens JF, Stöcklin J, Pluess AR (2010) Unifying selection acts on competitive ability and relative growth rate in Scabiosa columbaria. Basic Appl Ecol 11:612-618 
Scheepens JF, Frei ES, Stöcklin J (2013) Glacial history affected phenotypic differentiation in the Alpine plant Campanula thyrsoides. PLOS ONE 8:e73854

Shaw RG, Etterson JR (2012) Rapid climate change and the rate of adaptation: insight from experimental quantitative genetics. New Phytol 195:752-756

Shetler SG (1982) Variation and evolution of the Nearctic harebells (Campanula subsect. Heterophylla). J. Cramer, Vaduz

Stevens CJ, Wilson J, McAllister HA (2012) Biological Flora of the British Isles: Campanula rotundifolia. J Ecol 100:821-839

Therneau T (2012) A package for survival analysis in S. http://cran.r-project.org/package=survival

Turesson G (1925) The plant species in relation to habitat and climate. Hereditas 6:147-236

Turesson G (1930) The selective effect of climate upon the plant species. Hereditas 14:99-152

Vergeer P, Kunin WE (2013) Adaptation at range margins: common garden trials and the performance of Arabidopsis lyrata across its northwestern European range. New Phytol 197:989-1001

Volis S, Yabukov B, Shulgina I, Ward D, Mendlinger S (2005) Distinguishing adaptive from nonadaptive genetic differentiation: comparison of $Q_{\mathrm{ST}}$ and $F_{\mathrm{ST}}$ at two spatial scales. Heredity 95:466-475

Walther G-R (2003) Plants in a warmer world. Perspect Plant Ecol Evol Syst 6:169-185

Weber E, Schmid B (1998) Latitudinal population differentiation in two species of Solidago (Asteraceae) introduced into Europe. Am J Bot 85:1110-1112

Whitlock MC (2008) Evolutionary inference from $Q_{\mathrm{ST}}$. Mol Ecol 17:1885-1896 